\title{
Distal Bile Duct Cancer by AJCC v8 Stage
}

National Cancer Institute

\section{Source}

National Cancer Institute. Distal Bile Duct Cancer by A/CC v8 Stage. NCI Thesaurus. Code C134811.

A term that refers to the staging of distal bile duct cancer according to the American Joint Committee on Cancer, 8th edition. This staging system applies to bile duct adenocarcinomas, biliary intraepithelial neoplasia, high-grade neuroendocrine carcinomas, and papillary carcinomas. Tumors arising in the ampulla of Vater, sarcomas, and well-differentiated neuroendocrine tumors (carcinoids) are not staged using this staging system. (from AJCC 8th Ed.) 